\title{
DESENHO UNIVERSAL PARA APRENDIZAGEM: uma abordagem para alunos com autismo em sala de aula
}

\author{
Adriana Araújo Pereira Borges \\ Carlo Schmidt
}

\section{Resumo}

Embora o Transtorno do Espectro do Autismo (TEA) possa ser definido como um transtorno do neurodesenvolvimento, com déficits nas habilidades de comunicação e comportamento, o termo espectro retrata a enorme gama de diferenças individuais desses sujeitos. No ambiente escolar, essas diferenças tendem a ser evidenciadas, o que pode impactar no trabalho do professor com o aluno. Uma das possibilidades de intervenção para facilitar o processo de aprendizagem de educandos com TEA é o Desenho Universal para Aprendizagem (DUA). O DUA pode ser compreendido como um conjunto de princípios e estratégias que se relacionam com o currículo escolar. Sua finalidade é eliminar as barreiras que impedem o aprendizado, contribuindo para a inclusão escolar dos alunos, principalmente aqueles que constituem o público-alvo da educação especial. Nesse sentido, atua como facilitador da prática pedagógica. O objetivo desse artigo é discutir como o DUA pode auxiliar os aprendizes com autismo de acordo com as teorias da coerência central, das funções executivas e da teoria da mente (ToM). A importância dessa abordagem é percebida a partir da narrativa da mãe de um aluno com autismo sobre os entraves da escolarização do filho e sobre as práticas pedagógicas que contribuíram em seu percurso educacional. Os resultados apontam para a importância de que os professores conheçam e se apropriem do DUA, uma ferramenta que contribui para a inclusão escolar dos alunos com autismo e para uma prática pedagógica mais equitativa.

Palavras-chave: desenho universal para aprendizagem; autismo; educação especial; currículo.

UNIVERSAL LEARNING DESIGN: an approach for students with autism in the classroom

\begin{abstract}
Although Autism Spectrum Disorder (ASD) can be defined as a neurodevelopmental disorder, with deficits in communication and behavioral skills, the term spectrum portrays the enormous range of individual differences in these subjects. In the school environment, these differences tend to be evident, which may affect the work of the teacher with the student. One of the intervention possibilities to facilitate the student's learning process with ASD is the Universal Design for Learning (UDL). UDL can be understood as a set of principles and strategies that relate to the school curriculum. Its purpose is to eliminate the barriers that hinder learning, contributing to the school inclusion of students, especially those who are the target audience of special education. In this sense, it acts as a facilitator of pedagogical practice. The aim of this paper is to discuss how DUA can assist learners with autism according to weak central coherence (WCC), executive function and theory of mind (ToM) theories. The importance of this approach is perceived from the narrative of the mother of an autistic child about the obstacles to her son's schooling and about the pedagogical practices that contributed to her educational path. The results point to the importance for teachers to know and take ownership of UDL, a tool that contributes to the school inclusion of students with autism and to a more equitable pedagogical practice.
\end{abstract}

Keywords: universal design for learning; autism; special education; curriculum. 
DOI: $10.12957 /$ teias.2021.57044

\section{DISEÑO UNIVERSAL PARA EL APRENDIZAJE: un enfoque para estudiantes con autismo en el aula}

\section{Resumen}

Aunque el trastorno del espectro autista (TEA) puede definirse como un trastorno del neurodesarrollo, con déficits en la comunicación y las habilidades conductuales, el término espectro describe la enorme variedad de diferencias individuales en estos sujetos. En el ámbito escolar, estas diferencias suelen ser evidentes, lo que puede impactar en el trabajo del docente con el alumno. Una de las posibilidades de intervención para facilitar el proceso de aprendizaje de los estudiantes con TEA es el Diseño Universal para el Aprendizaje (DUA). La DUA puede entenderse como un conjunto de principios y estrategias que se relacionan con el currículo escolar. Su propósito es eliminar las barreras que dificultan el aprendizaje, contribuyendo a la inclusión escolar de los estudiantes, especialmente aquellos que son el público objetivo de la educación especial. En este sentido, actúa como facilitador de la práctica pedagógica. El propósito de este artículo es discutir cómo DUA puede ayudar a los estudiantes con autismo de acuerdo con las teorías de coherencia central, función ejecutiva y teoría de la mente (ToM). La importancia de este enfoque se percibe a partir de la narrativa de la madre de una alumna con autismo sobre las barreras para la escolarización de su hijo y sobre las prácticas pedagógicas que contribuyeron a su trayectoria educativa. Los resultados apuntan a la importancia de que los docentes conozcan y se apropien de la DUA, una herramienta que contribuye a la inclusión escolar de los estudiantes con autismo y a una práctica pedagógica más equitativa.

Palabras clave: diseño universal para el aprendizaje; autismo; educación especial; currículo.

\section{INTRODUÇÃO}

Em 1943, o psiquiatra austríaco radicado nos Estados Unidos da América, Léo Kanner, publica um artigo em que descreve de forma detalhada o quadro clínico de onze crianças que, segundo ele, eram incapazes de estabelecer relações normais com outras pessoas (KANNER, 1943/2012). Esse artigo revelou ao mundo as crianças autistas, que embora já existissem, não eram reconhecidas em suas características específicas. No final da década de 1970, Lorna Wing, juntamente com Judith Gould, publica uma série de artigos que redimensiona a questão do autismo. A síndrome não era tão hermética como Kanner pressupunha. Para elas, as características do autismo podiam aparecer combinadas de várias formas e com matizes infinitos de intensidade. Em 1988, Wing passa a utilizar o termo espectro para denotar essa ideia (DONVAN; ZUCKER, 2017).

Em 2013, o Manual Diagnóstico e Estatístico de Transtornos Mentais (DSM-5) passa a adotar o termo Transtorno do Espectro Autista (TEA), corroborando, dessa forma, a noção de que o autismo é um quadro extremamente complexo, pois existem autistas falantes e outros que nunca vão adquirir essa capacidade; autistas com uma inteligência acima da média e outros com déficits intelectuais graves; autistas que apresentam muitas dificuldades sensoriais e outros que possuem uma tolerância maior, e assim por diante. O autismo reflete, de forma dimensional, a diversidade que existe naturalmente. Essas diferenças tendem a ser evidenciadas no contexto escolar. A escola é uma instituição que, frequentemente, se organiza a partir da crença no "aluno médio". Mas esse "aluno médio é um mito, um artefato estatístico que não corresponde a nenhum indivíduo real” (MEYER et al., 2014, p. 2). Baseando-se nesse aluno médio inexistente, a escola constrói barreiras desnecessárias ao aprendizado.

Se antes os alunos com autismo estavam institucionalizados, hoje eles frequentam as escolas regulares. Segundo o Instituto Nacional de Educação e Pesquisa Anísio Teixeira (INEP, 2021), em 2020 havia 1,3 milhões de matrículas de alunos considerados Público-Alvo da Educação Especial (PAEE). Do total de alunos com deficiência matriculados nas escolas, 246.769 mil alunos 
apresentavam o diagnóstico de autismo. O percentual de matrículas de alunos incluídos em classes comuns aumentou gradativamente ao longo dos anos. Em 2016, o percentual de alunos incluídos era de $89,5 \%$ e, em 2020 , passou para 93,3\%.

A presença dos alunos com TEA na escola, bem como a de outros alunos com deficiência, exige uma mudança na forma de conduzir o processo de ensino-aprendizagem. Ela derruba o mito do "aluno médio" e provoca os professores. Para Omote (2018, p. 28), "Dois princípios norteadores podem ser fundamentais para a progressiva e interminável inclusão" - o desenvolvimento de recursos, materiais e procedimentos que precisa levar em consideração a diversidade dos usuários e a compreensão de que a existência das diferenças é de domínio e responsabilidade de toda comunidade.

A partir do momento em que as sociedades humanas vão evoluindo, novas demandas vão sendo criadas. Por isso, a inclusão é progressiva e interminável. Existe a necessidade de se desenvolver recursos, materiais e procedimentos que favoreçam esse processo. Nesse contexto, surge o DUA, como uma abordagem que favorece o acesso do aluno ao currículo. É importante compreender que todo estudante, com deficiência ou não, se beneficia de um currículo flexível e, portanto, dessa abordagem. No entanto, alunos com autismo, por conta de suas especificidades, podem ser ainda mais favorecidos. O objetivo desse artigo é discutir como o DUA pode auxiliar os aprendizes com autismo de acordo com as teorias da coerência central, das funções executivas e da teoria da mente (ToM).

\section{AS ESPECIFICIDADES DA APRENDIZAGEM DOS ALUNOS AUTISTAS}

A literatura mais recente tem destacado o quanto processos cognitivos atípicos podem contribuir para a expressão das características sociais e comportamentais das pessoas com TEA (JONES et al., 2018). Sendo o autismo uma condição cuja etiologia ainda não é completamente conhecida, pesquisadores têm buscado desenvolver modelos cognitivos que possam ajudar a compreender seus sintomas a partir dos déficits cognitivos subjacentes. Portanto, esclarecer as associações entre comportamentos e cognições no autismo é um passo importante para identificar as especificidades de aprendizagem e de comportamentos que possam se constituir como barreiras à aprendizagem destes alunos no cenário escolar. Algumas teorias têm se dedicado a lançar luz sobre essa questão, dentre as quais três têm recebido destaque: a teoria da mente, as funções executivas e a coerência central.

A Teoria da Mente (ToM), oriunda da área da psicologia do desenvolvimento, é definida como a habilidade de inferir estados mentais de outras pessoas e usar estas informações para prever seu comportamento (BEEGER et al., 2015). Quanto às interações, a compreensão na ToM é recíproca, pois os indivíduos atribuem estados mentais como causa e efeito de ações e comportamentos, incluindo como estes afetam o estado mental de outras pessoas e suas ações subsequentes, e vice-versa (HUTCHINS et al., 2016). Essa capacidade de interpretar os pensamentos, crenças e desejos que motivam comportamentos e ações é fundamental para a compreensão dos outros no cotidiano escolar, o que interfere não somente nas relações sociais, mas também na aprendizagem escolar dos alunos com autismo (WHALON, COX, 2020). Mais especificamente, as habilidades cognitivas associadas à ToM (ex.: tomada de perspectiva, inversão de papéis, flexibilidade cognitiva) têm se relacionado diretamente com a aprendizagem escolar, sendo preditivas do desenvolvimento de habilidades acadêmicas, incluindo habilidade de leitura e matemática (KIM et al., 2018; WELLMAN, 2017). 
No contexto escolar, o desafio dos professores diz respeito não apenas a promover o desenvolvimento das competências sociais centrais dos alunos com autismo, mas também o acesso ao currículo e aos conteúdos acadêmicos pertinentes a cada etapa de escolarização. Embora possam parecer objetivos docentes distintos e paralelos, a competência social é altamente preditiva do desempenho acadêmico, mostrando as relações estreitas entre as dificuldades sociais e de aprendizagem (MONTROY, 2014). Quanto às aprendizagens acadêmicas ou dos conteúdos curriculares, as habilidades de leitura, escrita e matemática variam bastante entre alunos com TEA, justamente pela heterogeneidade do espectro do autismo. Por exemplo, não é incomum que esses alunos desenvolvam habilidades de leitura aos três anos de idade, mesmo com severas dificuldades de comunicação (BALDAÇARA et al., 2006). Por outro lado, alunos com TEA são mais propensos a apresentar dificuldades do que habilidades acima da média na aprendizagem da matemática (OSWALD et al., 2016).

A segunda teoria que nos auxilia a entender algumas especificidades da construção das aprendizagens de alunos com TEA versa sobre as funções executivas, que podem ser definidas como "um conjunto de habilidades cognitivas que permitem ao sujeito engajar-se em comportamentos orientados a objetivos, realizando ações voluntárias, independentes, autoorganizadas e direcionadas a metas" (DIAS, MENEZES, SEABRA, 2010, p. 81). Esta teoria neuropsicológica ganha relevo no contexto do autismo quando defende que as dificuldades no controle executivo poderiam estar relacionadas a alguns dos comprometimentos cognitivos e comportamentais observados em indivíduos com diversos transtornos, incluindo o TEA (CZERMAINSKI, BOSA, SALLES, 2013). De fato, alunos com autismo tendem a apresentar dificuldades na inibição de respostas, planejamento, controle atenção e flexibilidade cognitiva, o que se reflete tanto nas dificuldades de interação social, comunicação e comportamentos típicos do TEA como no processo de aprendizagem na escola (CORSO et al., 2013). As funções executivas começam a se desenvolver nos primeiros anos de vida e terminam seu processo de maturação por volta do final da adolescência. $O$ desenvolvimento dessas funções durante este período proporciona gradualmente a adequação e um melhor desempenho para a iniciação, persistência e conclusão de tarefas (GOMES et al., 2014). Importante destacar que falhas ou atrasos nessas mesmas habilidades estão presentes nas dificuldades de aprendizagem de alunos sem autismo, mostrando como elas são centrais para a consolidação da aprendizagem. Mas acima de tudo, estas habilidades são especialmente importantes diante de situações novas ou em circunstâncias que exigem ajustamento, adaptação ou flexibilidade do comportamento para as demandas do ambiente, como no caso da escola. Portanto, a criança com TEA necessitará, em maior ou menor medida, um apoio que as auxiliem a lidar com demandas frequentemente presentes na escola como o planejamento, a organização, a autorregulação, a autoavaliação e a tomada de decisões.

Por fim, a terceira teoria explicativa sobre as características de aprendizagem no autismo é a chamada Teoria da Coerência Central. Foi desenvolvida originalmente por Uta Frith, uma pesquisadora de naturalidade alemã, no laboratório de neurociência cognitiva da University College of London. A coerência central, segundo Frith (1989), se refere ao estilo de processamento cognitivo no autismo, mais especificamente, uma ausência da tendência natural em juntar partes de informações para formar um todo provido de significado (HAPPÉ, FRITH, 2006). De acordo com este estilo cognitivo, pessoas com autismo apresentariam uma capacidade limitada para entender o contexto social maior, ou seja, de compreender o todo, tendo uma habilidade melhor para perceber as partes.

Frith (1989) chamou a atenção para uma tendência natural de crianças e adultos sem autismo em processarem as informações do seu ambiente em busca de um significado mais amplo, 
geralmente à custa da atenção ou da memória para então, secundariamente, compreenderem os detalhes mais superficiais. Essa tendência foi referida por Bartlett (1932) como "busca de significado" e denominada por Frith (1989) como "coerência central". Em síntese, Frith (1989) propôs que pessoas com TEA possuem uma "coerência central fraca", detendo-se mais nos detalhes do que no quadro geral, e por isso chamado de "estilo cognitivo focado nos detalhes". Diferentemente das teorias da mente e das funções executivas, apresentadas anteriormente, a teoria da coerência central não explica apenas os déficits das pessoas com autismo, mas também suas habilidades e pontos fortes, entendendo essa característica não como inferior ao processamento típico, mas apenas diferente deste.

O conhecimento das peculiaridades - que envolvem o modo como as pessoas com autismo aprendem - é essencial para que os professores possam planejar práticas pedagógicas que permitam o acesso pleno desses alunos ao currículo escolar. Uma abordagem especialmente relevante neste sentido é o Desenho Universal para Aprendizagem.

\section{DESENHO UNIVERSAL PARA APRENDIZAGEM}

Em 1984, um grupo formado pelos pesquisadores Anne Meyer, David Rose e David Gordon, fundou o CAST (Center of Applied Special Technology) [Centro de Tecnologia Especial Aplicada]. No início, o grupo se dedicou a entender e aplicar as novas tecnologias para a educação de crianças com deficiência. Por volta dos anos 1990, o foco mudou: a abordagem deixou de ser as deficiências dos alunos e passou a ser a deficiência das escolas. Essa nova abordagem recebeu o nome de Universal Design for Learning (UDL). Em português, o Desenho Universal para Aprendizagem (DUA). Essa abordagem teve como base pesquisas em educação e neurociência, aproveitando a flexibilidade que a tecnologia proporciona, com a finalidade de tornar a educação mais justa e eficaz (MEYER et al., 2014). O DUA tem como objetivo o desenvolvimento de práticas pedagógicas que permitam o acesso ao currículo. As práticas pedagógicas se diferenciam de práticas educativas. Enquanto as práticas educativas se referem às práticas que ocorrem no sentido de concretizar os processos educacionais, as práticas pedagógicas se referem às práticas sociais que se exercem com a finalidade de concretizar os processos pedagógicos (FRANCO, 2017).

Dessa forma, as práticas pedagógicas podem ser compreendidas como aquelas que se organizam intencionalmente para atender determinada demanda social. Atualmente no Brasil, todas as escolas comuns devem receber alunos com deficiência, incluindo os alunos com TEA. O DUA é um modelo de intervenção que leva em consideração a diversidade da sala de aula, compreendendo que todo aluno, independentemente de sua condição, deve ter sucesso na aprendizagem. Ou seja, a abordagem do DUA permite que alunos com deficiência, como os alunos com TEA que tem especificidades em termos de aprendizagem, possam acompanhar o currículo, pois o importante nessa concepção, não é se o material em si é acessível, mas se a aprendizagem para qual o material ou atividade é projetada é acessível (HITCHCOCK et al., 2002). Na concepção do DUA, o currículo é entendido como metas de aprendizado, os meios de avaliação, os métodos de ensino e os materiais. E para que a aprendizagem seja acessível, o DUA prioriza redes de aprendizagem. Redes afetivas, que ajudam a definir prioridades, motivar e envolver aprendizado e comportamento; redes de reconhecimento, que transformam as informações em conhecimento utilizável e redes estratégicas, que trabalham a intencionalidade das ações a partir do planejamento e organização (MEYER et al., 2014)

A opção por essas redes de aprendizagem não é por acaso. Vigotski já havia descrito no início do século XX três requisitos para a aprendizagem: envolvimento com a tarefa de 
aprendizado, reconhecimento das informações a serem aprendidas e estratégias para processar essas informações. Benjamin Bloom optou por dividir os objetivos educacionais em três áreas muito semelhantes: cognitiva, psicomotora e afetiva (MEYER et al., 2014). A taxonomia de Bloom contribui bastante com o DUA. O sistema consiste numa classificação em seis níveis, que vão do mais simples ao complexo. De acordo com Bloom, níveis mais altos de cognição são alcançados quando se pede aos estudantes que respondam perguntas de alto nível, que requerem mais do que memorização e aplicação. Ele propôs então, perguntas que podem ser categorizadas em dois tipos, as que usam habilidades de pensamento de baixo nível (conhecimento, compreensão e aplicação) e as de alto nível (análise, síntese, avaliação). Cada nível possui tipos de perguntas que podem ser realizadas e os verbos que devem ser utilizados. Por exemplo, se o nível que o professor deseja alcançar com o aluno é do conhecimento, as perguntas podem ser: Quem? Quando? Onde? Nomeie. Descreva. E os verbos seriam: organize, cite, encontre, localize. Mas se o professor deseja que em determinada atividade o aluno utilize níveis mais altos de cognição, como na análise, ele deve fazer perguntas como: O que se pode concluir? Qual a ideia secundária? Qual a função? E os verbos: Contraste, compare, classifique, infira. A taxonomia permite que o planejamento das atividades leve em consideração o nível de cada aluno (VALLE, CONNOR, 2014). As mesmas atividades são apresentadas, mas as diferenças individuais são consideradas. A abordagem do DUA utiliza as ferramentas necessárias para que a aprendizagem possa ocorrer, como a taxonomia de Bloom.

Fundamental na abordagem, é a noção de que é necessário considerar: o porquê da aprendizagem, fornecendo vários meios de engajamento; o quê da aprendizagem, fornecendo meios variados de representação e o como da aprendizagem, fornecendo vários meios de expressão e ação (MEYER, 2014). Esses são os princípios do DUA. Nessa abordagem, o professor deve ser flexível. É ele que vai apresentar o currículo levando em consideração a heterogeneidade da sala de aula. O primeiro princípio diz que é necessário estimular o interesse dos alunos e motivá-los para a aprendizagem recorrendo a múltiplos meios de envolvimento. Dentro desse princípio é muito importante o conceito de autorregulação, ou seja, a capacidade de estabelecer metas motivadoras, sustentar os esforços para atingi-las e monitorar o equilíbrio entre as demandas internas e externas, ajustando expectativas e estratégias ou pedindo ajuda, quando necessário (MEYER, 2014). Esse conceito é importante para que todos professores compreendam que os alunos são diferentes, independentemente de terem uma deficiência ou não. O espectro demonstra que existem desde alunos com interesses muito específicos, que devem ser aproveitados sempre, até alunos não verbais que precisam ser trabalhados em aspectos muito específicos da autorregulação.

O segundo princípio se refere ao quê da aprendizagem. É necessário apresentar a informação e o conteúdo em múltiplos formatos para que todos tenham acesso ao currículo, ou seja, ampliar as opções de representação, fornecendo opções de percepção, de linguagem, expressões matemáticas e símbolos e opções para compreensão (MEYER, 2014). Esse princípio também é adequado às características de aprendizagem de alunos com TEA, que, de modo geral, tendem a responder melhor a estímulos visuais do que auditivos (O'CONNOR, HERMELIN, 1965). É importante salientar que, apesar de a tecnologia ser uma aliada em toda abordagem do DUA, não se trata de simplesmente entregar um computador para cada criança. Os materiais só importam na medida em que cumprem a função de auxiliarem a aprendizagem. "Transformar a experiência da escola para atender à variabilidade do aluno exige a percepção de que nenhum meio de representação é ideal para todos os alunos, todas as áreas de estudo ou todas as circunstâncias" (MEYER et al., 2014, p. 54). 
O terceiro princípio é o que permite formas alternativas de expressão e de demonstração das aprendizagens por parte dos alunos. Os alunos são avaliados de forma diferente e se levam em consideração suas potencialidades. Enquanto alguns alunos são avaliados por meio da escrita, outros podem fazer uma apresentação do que aprenderam. Os meios podem ser os mais diversos, incluindo desenhos, músicas e a utilização de tecnologia assistiva. Para cada um dos princípios, há uma série de diretrizes e pontos de verificação que ajudam os educadores a projetarem instruções para atender às necessidades de uma ampla variedade de alunos.

A abordagem do DUA não exclui a importância do Plano de Desenvolvimento Individual (PDI) ou Plano de Ensino Individualizado (PEI). A palavra universal, no Desenho Universal para Aprendizagem, costuma confundir. A princípio, parece que universal significa o mesmo para todos. E não é disso que se trata no DUA, pelo contrário. A palavra universal se refere ao respeito às características individuais dos alunos. O fundamental na abordagem do DUA é o entendimento de que cada aluno tem necessidades únicas e aprende de forma diferente. Não existe uma solução única para todos e a estrutura do DUA facilita o acesso do aluno ao currículo através do reconhecimento das diferenças individuais.

\section{O ESPECTRO DO AUTISMO E O DESENHO UNIVERSAL PARA APRENDIZAGEM}

TEA e DUA: “Onde o autismo se encaixa nisso? O termo TEA ${ }^{1}$ é usado para identificar indivíduos cujos interesses e habilidades de comunicação, sociais e executivas diferem amplamente dos alunos que estão se desenvolvendo normalmente" (DOMINGS et al., 2014, p. 9). Além disso, a variabilidade no espectro é muito grande. A principal vantagem da abordagem do DUA é que está presente em sua concepção o entendimento de que as pessoas são diferentes.

As salas de aula tradicionais, frequentemente, têm um único meio de representar informações (texto, aula expositiva etc.), um meio de agir e expressar o que os alunos sabem (ouvindo, lendo e pela escrita) e um meio de envolver os alunos com a aprendizagem (apresentando um tópico que pode ou não ser interessante para todos) (DOMINGS et al., 2014). Essa organização do ensino não atinge a diversidade de alunos da sala de aula, incluindo os alunos com TEA. Para discutir a importância do DUA como uma abordagem estratégica na educação de alunos com autismo, será apresentado o caso de $\mathrm{Marco}^{2}$, a partir dos fragmentos de uma entrevista realizada com sua mãe, Suzana (nome fictício) a respeito de sua escolarização.

Marco (nome fictício), 25 anos, foi diagnosticado com Síndrome de Asperger. Enfrentou inúmeros problemas na escolarização, desde a educação infantil. No ensino fundamental, o professor de educação física chamou a mãe e disse que ele não precisaria mais participar das aulas, que teria a presença registrada mesmo assim. Ele não era bom em educação física, por isso foi convidado a se retirar da turma. Na mesma época, a mãe foi chamada na escola de línguas. $\mathrm{O}$ professor estava incomodado, pois ele sempre sabia as respostas das questões, se adiantava, questionava a pronúncia. O professor sugeriu que ele fizesse aulas individuais. Marco era bom demais em línguas, por isso foi convidado a se retirar da turma:

\footnotetext{
${ }^{1}$ Em inglês, ASD (Autism Spectrum Disorder).

2 A entrevista citada nesse artigo foi realizada com Suzana, mãe de Marco (nomes fictícios) no âmbito de uma pesquisa que ouviu familiares de pessoas com deficiência sobre o processo de escolarização desses alunos. Pesquisa aprovada pelo Comitê de Ética em Pesquisa da Universidade Federal de Minas Gerais, registro 96237418.2.0000.5149.
} 
Entendeu?! Deu problema, você tira. Se tá bom, você tira. Todas as vezes que tinha uma barreira, a gente estava falando de barreira atitudinal, essa barreira nunca foi retirada ou transposta, eles tiravam o Marco (Suzana).

Marco não era o "aluno médio" que a escola queria. Ele precisava de suportes para superar os déficits e de suplementação para aprimorar os dons. Não teve nenhuma das duas coisas de uma forma planejada e sistematizada, pois ele deveria se encaixar no currículo. Hoje, ele tem proficiência em inglês, por Cambridge; em japonês, pelo Consulado do Japão, é muito bom em espanhol e latim. Para isso, o suporte da família foi fundamental. Mas a literatura tem nos mostrado que Marco é somente um dos milhares de alunos com TEA que passam pela escola sem serem reconhecidos em suas características individuais.

Em 2019, Luíza Vicari realizou uma pesquisa em uma escola pública de educação básica. Ela observou dois alunos com autismo em duas salas de aula diferentes do primeiro ciclo, sendo que ambos contavam com auxiliares de apoio. Nas duas salas, ela percebeu atitudes parecidas. Nas duas salas, os alunos sentavam na última fileira, distantes da professora. Um dos alunos realizou durante o período de observação ( 7 dias), 21\% das atividades iguais às da turma com autonomia. Em 30\% das atividades, ele precisou de ajuda, não participando de $43 \%$ das atividades. A auxiliar realizou as atividades por ele em 19\% das vezes. O segundo aluno foi observado em 8 dias. Nesse período, enquanto o aluno realizou 47 atividades, o restante da turma realizou 97 atividades. Outra constatação da pesquisa foi que, na maior parte das vezes, o aluno não fez o que a turma fazia e nem recebia atividades planejadas. Por vezes, os alunos ficavam brincando em suas carteiras com brinquedos que trouxeram de suas casas, ou com o material escolar. Vicari (2019) aponta que:

As professoras, em geral, apresentavam os conteúdos de maneira expositiva, ficando de frente para a turma, lendo um livro de literatura ou realizando outra atividade estruturada. Foram comuns exercícios de cópia do quadro e exercícios nos livros didáticos. A rotina da turma se dividia em atividades organizadas em sala, lanche no refeitório, recreio na quadra, repouso em classe. Nesse momento, os alunos deitavam a cabeça em cima da mesa para descansar da volta do recreio e, em seguida, eram feitas atividades em livros ou em material preparado para a turma (VICARI, 2019, p. 120).

Gonzaga (2019) também realizou uma pesquisa a partir de registros das atividades realizadas por alunos com autismo, a maior parte matriculada em escolas privadas. A pesquisa avaliou os registros das atividades de 30 alunos. Durante o período de um mês, apenas um dos alunos realizou todas as atividades iguais as da turma. Isso não seria problema se os professores tivessem planejado atividades para os alunos com autismo. A pesquisa apontou para o alto índice de atividades individuais, diferentes da turma e sem planejamento, realizadas pelos alunos autistas.

Em sua pesquisa, uma das crianças passou um mês inteiro sem realizar nenhuma atividade igual à da turma. O mais impressionante nessa constatação, é o fato de que todas as atividades foram contabilizadas pela pesquisadora, inclusive o recreio e o lanche. Ou seja, durante um mês inteiro, o aluno com TEA não fez nenhuma atividade igual à da turma, incluindo lanchar. Embora tenham chegado cada vez mais nas escolas regulares, esses alunos continuam sendo ignorados pelo sistema educacional, independentemente de estudarem na rede pública ou em escolas privadas. É necessário e urgente adotar abordagens que possam, realmente, incluir os alunos nas escolas. $\mathrm{O}$ acesso ao ambiente físico da escola regular não é suficiente, é necessário que sejam contempladas as especificidades de aprendizagem dos alunos na sala de aula. 
O DUA trabalha com planejamento. É preciso ter objetivos claros quanto ao aprendizado dos estudantes. Esses objetivos devem ser pensados ao longo do tempo: nos próximos 10 minutos, na próxima lição, no próximo ano... (MEYER et al., 2014). Entusiasmo pela aprendizagem e autorregulação devem estar presentes. Os alunos devem ser motivados a aprender. Conhecendo o aluno, o professor pode traçar objetivos, destacando que os desafios são importantes no DUA; no entanto, o DUA leva em consideração que os alunos precisam de um equilíbrio entre desafios e apoio (HITCHCOCK et al., 2002). Dessa forma, o currículo da turma é sempre a referência, mas são ofertados aos alunos meios diversificados de apresentação do conteúdo, para poderem trabalhar esses conteúdos em formatos diferentes, priorizando seu envolvimento no processo.

Dois pontos importantes nessa abordagem: o primeiro orienta que o ensino deve ser cooperativo e não competitivo. As vantagens do trabalho cooperativo se estendem à aquisição de conceitos e de resolução criativa de problemas, contribuindo para a aquisição de várias habilidades como as sociais e linguísticas (COHEN, LOTAN, 2017). A cooperação pressupõe um trabalho em grupo. O aluno com TEA, bem como alunos típicos, necessita de uma mediação para estabelecer contato com os colegas e aprender a trabalhar de forma cooperativa, mas todos ganham com a experiência.

O segundo diz respeito à organização da classe, que pode ter diferentes arranjos dependendo dos objetivos da aula, ou seja, a flexibilização do ambiente escolar. Na pesquisa de Vicari (2019), chama a atenção o fato de que nas duas salas, em todos os dias de observação, as carteiras dos estudantes se mantiveram organizadas da mesma forma: em fila. A maioria das escolas brasileiras ainda mantém essa padronização, que não auxilia os estudantes. Embora a rotina e a organização do ambiente sejam importantes para o aluno com autismo, sentar afastado nos últimos lugares não é o mais apropriado. Essa rigidez demonstrada na pesquisa de Vicari (2019), contrasta com o depoimento de Suzana, a respeito de Marco, ao se referir ao início de sua escolarização, em uma escola específica:

[...] Aí ele saiu e foi para uma escola pequena, na sala dele tinham umas oito crianças, mais ou menos. E ali eles deixaram o Marco mais à vontade. Por exemplo, ele só desenhava com o lápis verde e só sentava na cadeira verde. $\mathrm{Na}$ outra escola, eles criaram caso porque ele tinha que saber dividir, então ele não podia sentar só na cadeira verde, um dia ele sentava na verde, outro dia na amarela... E ele não podia desenhar só com o lápis verde, ele tinha que usar todos os lápis, mas ele só gostava do verde. E nessa escola eles deixavam ele desenhar só com o verde, sentar só na verde [... ]. Eles compreendiam mais. Porque eu acho que a questão da dificuldade é você encontrar pessoas que têm sensibilidade suficiente, eu acho que nem precisava de ter curso nenhum, o curso ajuda, mas a sensibilidade é o fundamental (Suzana)

Como se observa no relato, Marco tinha uma fixação pela cor verde. Na abordagem do DUA, embora o trabalho em grupo seja incentivado e a flexibilidade no ambiente seja desejável, o respeito à individualidade é fundamental. Se Marco prefere se sentar na cadeira verde, tudo bem! O que chama a atenção nas situações, é como a escola tradicionalmente funciona, com lugares marcados e uma rigidez no ambiente e o contraste com a situação diversa, em que o aluno demonstra essa rigidez, mas é confrontado de forma categórica para que mude de lugar.

Ele já teve problemas sérios com algumas professoras, de professora não admitir que ele ficasse com aquela postura, que ele tinha que ficar com postura de sala de aula, e elas iam lá, pegavam a mão dele e ensinavam que tinha que pegar no lápis daquela forma e ele pegava mais fechado, ele dizia que não conseguia... E 
DOI: $10.12957 /$ teias.2021.57044

fazia caderno de caligrafia, então acabava virando uma tortura. E foi indo assim (Suzana).

Marco ficava deitado na carteira, uma estratégia para conseguir se organizar sensorialmente na escola. Mas isso não era permitido, era preciso sentar da mesma forma que os outros, da forma considerada correta. O mesmo em relação à escrita. A letra deveria ser caprichada, treinos intermináveis no caderno de caligrafia.

Com isso, esses profissionais que assistiam o Marco fora de aula, ajudaram muito. Porque eles diziam "Não adianta fazer caderno de caligrafia! A questão dele é motora, ele não vai melhorar, ele não vai caprichar na letra. O problema dele não é capricho, não é isso. Ele vai fazer dessa forma”. Então, eles foram adaptando para o Marco de uma forma [...]. Por exemplo, ele fazia prova e a professora não entendia nada da prova. Então o que ela fazia? Ela pedia ao Marco para ele ler a prova para ela (Suzana).

Se a professora não consegue ler o que o aluno escreveu, por que ele mesmo não pode ler? Ao proporcionar meios alternativos de expressão, a professora permitiu que o aluno expressasse seu conhecimento. Portanto, o DUA é uma abordagem acessível, mas que necessita de uma mudança atitudinal por parte da escola.

Então eles faziam isso muitas vezes e tinha uma professora de português, que era até engraçado, isso ele já era até maior. Ela começou a perceber, que quando ela colocava a letra dele de longe, todo mundo lia. Então ela ensinou os outros professores a ler a letra do Marco. Eu acho que assim, o professor, ele tem muito esse papel de conhecer o aluno (Suzana).

É preciso conhecer os alunos, principalmente aqueles que têm alguma deficiência. O PDI ou PEI, na perspectiva do DUA é fundamental, pois permite conhecer o aluno. É importante propiciar um currículo onde o desafio seja apropriado, o aluno deve aprender, mas não deve sofrer para aprender. É preciso ter metas para o aprendizado e o DUA permite eliminar as barreiras para o acesso ao currículo e a participação na sala de aula. O objetivo do DUA não é reduzir todo o esforço do aluno, mas reduzir o esforço desnecessário, aquele que distrai e que incapacita. "Quando os objetivos não restringem desnecessariamente os caminhos para o sucesso, todos os alunos progridem com eles" (HITCHCOCK et al., 2002, p. 14).

Para ativar o aprendizado é necessário oferecer desafios apropriados, garantindo demandas altas o suficiente para exigir que o aluno se esforce além de seu repertório atual de habilidades e compreensão. Contudo, as exigências não podem ser tão altas que sobrecarreguem a capacidade do aluno de alcançar o objetivo instrucional. E se um aluno não apresentar imediatamente os recursos internos necessários para um bom desempenho no ambiente de aprendizagem, o educador deve fornecer suportes para reduzir o excesso de demandas sem reduzir as expectativas (DOMINGS et al., 2014). O DUA exige que o professor tenha uma formação adequada, pois realiza mudanças na cultura da sala de aula. É necessário conhecer os alunos e suas especificidades para ter em mente os objetivos, metas e estratégias que facilitem sua aprendizagem. Mas o DUA é uma abordagem acessível. Embora dê ênfase ao uso das tecnologias, é importante observar que estas são incentivadas por serem suportes eficazes e estarem cada vez mais presentes no dia-a-dia de todos. As orientações do DUA encontram-se disponíveis e podem ser aplicadas em qualquer escola, beneficiando a todos. 


\section{CONCLUSÃO}

O aluno com TEA na escola convoca todos a mudarem a forma de ensinar. Tradicionalmente, a escola se organiza de uma forma rígida, onde os alunos sentam em lugares marcados, enfileirados, o professor conduz a aula e os alunos recebem o aprendizado. $O$ aluno com TEA vem mostrar para a escola que existem outros canais sensoriais de aprendizado tão importantes quanto a audição e a visão. Que é necessário aumentar o repertório de recursos para o ensino, não se limitando ao livro didático ou ao quadro. Que as pessoas aprendem de formas diferentes e que mesmo entre os alunos com autismo, existe uma enorme variabilidade nas formas de aprender.

O grande desafio na educação do aluno com TEA é fazer com que as atitudes que foram tomadas, pontualmente, no processo de escolarização de Marco, como a leitura de seus textos por ele mesmo, a permissão para sentar num determinado lugar, ou ainda, o distanciamento de sua escrita para a compreensão da leitura de seu texto, não sejam atitudes casuais, mas que sejam planejadas, que constem em seu Plano de Desenvolvimento Individual. Portanto, esperamos que os princípios do DUA sejam priorizados quando se trata da escolarização de alunos com autismo e que as demandas desses educandos sejam amparadas por teorias como as descritas nessa pesquisa. Do mesmo modo, que estudos futuros possam descrever a utilização das estratégias do DUA em um grupo de escolares com autismo, ampliando os achados apresentados até então.

Ao organizar o ensino levando em conta as múltiplas possibilidades de aprendizagem, o professor atende a diversidade de todos os alunos, incluindo aqueles que tenham deficiências ou altas habilidades. Dessa forma, o DUA é uma abordagem que favorece a aprendizagem dos alunos, tenham ou não deficiência.

\section{REFERÊNCIAS}

ASSOCIAÇÃO PSIQUIÁTRICA AMERICANA (APA). Manual Diagnóstico e Estatístico de Transtornos Mentais. Porto Alegre; Artmed, 2014.

BALDAÇARA, Leonardo; NÓBREGA, Luciana; TENGAN, Sérgio K..; MAIA, Anne. Hiperlexia em um caso de autismo e suas hipóteses. Archives of Clinical Psychiatry, v. 33, n. 5, p. 268-271, 2006.

BARTLETT, Frederic. Remembering: a study in experimental and social psychology. Cambridge, England: Cambridge University Press, 1932.

BEGEER, Sender. et al. Effects and moderators of a short theory of mind intervention for children with autism spectrum disorder: a randomized controlled trial. Autism Research, v. 8, p. 738-748, 2015.

COHEN, Elizabeth; LOTAN, Rachel. Planejando o trabalho em grupo. 3. ed. Porto Alegre: Penso, 2017.

CORSO, Helena Velinho; SPERB, Tania Mara; JOU, Graciela Inchausti de; SALLES, Jerusa Fumagalli. Metacognição e funções executivas: relações entre os conceitos e implicações para a aprendizagem. Psicologia: Teoria e Pesquisa, v. 29, n. 1, p. 21-29, 2013.

CZERMAINSKI, Fernanda Rasch; BOSA, Cleonice Alves; SALLES, Jerusa Fumagalli. Funções executivas em crianças e adolescentes com transtorno do espectro do autismo: uma revisão. Psico, v. 44, n. 4, p. 518-525, 2013. 
DIAS, Natália Martins; MENEZES, Amanda; SEABRA, Alessandra Gotuzo. Alterações das funções executivas em crianças e adolescentes. Estudos interdisciplinares em Psicologia, v. 1, n. 1, p. 8095, 2010.

DOMINGS, Yvonne; CREVECOEUR, Yvel C.; RALABATE, Patricia. K. Universal design for learning. Meeting the needs of learners with autism spectrum disorders. In: BOSER, Katharina; GOODWIN, Matthew; WAYLAND, Sarah. C. (orgs.). Technology tools for students with autism. Innovations that enhance independence and learning. Baltimore: Paul Brookes Publishing, 2014, p. 21-41.

DONVAN, Jonh; ZUCKER, Caren. Outra sintonia: a história do autismo. Trad. Luiz A. de Araújo. 1. ed. São Paulo: Companhia das Letras, 2017.

FRANCO, Maria Amélia Santoro. Práticas pedagógicas de acolhimento e inclusão: a perspectiva da pedagogia crítica. Revista online de Política e Gestão Educacional, v. 21, n. 2, p. 964-978, 2017.

FRITH, Uta. Autism: explaining the enigma. Blackwell, 1989.

GOMES, Roberta de Figueiredo; SCHMIDT, Carlo; PEREIRA, Adriana; VASQUES, Adriana; FAGUNDES, Valéria. Autismo e funções executivas: prejuízo no lobo frontal. EFDeportes, n. 188, 2014.

GONZAGA, Mariana Viana. Análise da situação de inclusão de alunos com transtorno do espectro autista a partir de registro escolar diário. 116 folhas. Dissertação de mestrado (Programa de Pós-Graduação em Educação: Conhecimento e inclusão social) Universidade Federal de Minas Gerais, Belo Horizonte, MG, 2019.

HAPPÉ, Francesca; FRITH, Uta. The Weak Coherence Account: Detail-focused Cognitive Style in Autism Spectrum Disorders. Journal of Autism Developmental Disorders, v. 36, p. 5-25, 2006.

HITCHCOCK, Chuck; MEYER, Anne; ROSE, David; JACKSON, Richard. Providing new access to the general curriculum: universal design for learning. Teaching Exceptional Children, v. 35, n. 2, p. 8-17, 2002.

HUTCHINS, Tiffany L. et al. Explicit vs. applied theory of mind competence: a comparison of typically developing males, males with ASD, and males with ADHD. Research in Autism Spectrum Disorders, v. 21, p. 94-108, 2016.

INSTITUTO NACIONAL DE ESTUDOS E PESQUISAS EDUCACIONAIS ANÍSIO TEIXEIRA (INEP). Censo Escolar, 2020. Brasília/DF: MEC, 2021.

JONES, Catherine; SIMONOFF, Emily; BAIRD, Gilian; PICKELS, Andrew; MARSDEN, Anita; TREGAY, Jenifer; HAPPÉ, Francesca; CHARMAN, Tony. The association between theory of mind, executive function, and the symptoms of autism spectrum disorder. Autism Research, v. 11, n. 1, p. 95-109, 2018.

KANNER, Leo. Os distúrbios autísticos do contato afetivo. In: ROCHA, P. S. (ed.). Autismos. São Paulo: Escuta, 2012. p. 111-183.

KIM, Ha Yeom; LARUSSO, Maria; HSIN, Lisa; HARBAUGH, Allen. Social perspective-taking performance: construct, measurement, and relations with academic performance and engagement. Journal of Applied Developmental Psychology, v. 57, p. 24-41, 2018.

MEYER, Anne; ROSE, David; GORDON, David. Universal design for learning: theory and practice. Wakefield MA: CAST, 2014. 
MONTROY, Jannele; BOWLES, Ryan; SKIBBE; Lori; FOSTER, Tricia. Social skills and problem behaviors as mediators of the relationship between behavioral self-regulation and academic achievement. Early Childhood Quarterly, v. 29, p. 298-309, 2014.

O'CONNOR, Neil; HERMELIN, Beate. Sensory dominance in autistic imbecile children and controls. Archives of General Psychiatry, v. 12, p. 99-103, 1965.

OMOTE, Sadao. Atitudes Sociais em Relação à Inclusão: Recentes Avanços em Pesquisa. Revista Brasileira de Educação Especial, Bauru, v. 24, p. 21-32, 2018.

OSWALD, Tasha; BECK, Jonathan; IOSIF, Ana Maria; MCCAULEY, James; GILHOOLY, Leslie; MATTER, John; SOLOMON, Marjorie. Clinical and cognitive characteristics associated with mathematics problem solving in adolescents with autism spectrum disorder. Autism Research, v. 9, p. 480-490, 2016.

VALLE, Jan; CONNOR, David. Ressignificando a deficiência: da abordagem social às práticas inclusivas na escola. Trad. por Fernando Siqueira Rodrigues. Porto Alegre: AMGH. 2014.

VICARI, Luíza Leão Pinheiro. Escolarização de Alunos com TEA: práticas educativas em uma rede pública de ensino. 165fls. Dissertação de mestrado (Programa de Pós-Graduação em Educação: Conhecimento e inclusão social) Universidade Federal de Minas Gerais, Belo Horizonte, MG, 2019.

WELLMAN, Henry. The development of theory of mind: historical reflections. Child Development Perspectives, v. 11, p. 207-214, 2017.

WHALON, Kelly; COX, Sarah. The role of theory of mind and learning of children with Autism spectrum disorders in classroom settings. Educação Temática Digital, v. 22, p. 10-26, 2020.

\section{Informações do(a)(s) autor(a)(es)}

Adriana Araújo Pereira Borges

Universidade Federal de Minas Gerais

E-mail: adriana.borges@terra.com.br

ORCID: https://orcid.org/0000-0003-0493-0099

Link Lattes: http://lattes.cnpq.br/9946652387882951

Carlo Schmidt

Universidade Federal de Santa Maria

E-mail: carlopsico4@gmail.com

ORCID: https://orcid.org/0000-0003-1352-9141

Link Lattes: http://lattes.cnpq.br/7185372980306847 